\title{
Erratum to: When Confidence Is Not a Signal of Knowing: How Students' Experiences and Beliefs About Processing Fluency Can Lead to Miscalibrated Confidence
}

\author{
Bridgid Finn $^{1} \cdot$ Sarah K. Tauber ${ }^{2}$
}

Published online: 14 July 2015

(C) Springer Science+Business Media New York 2015

\section{Erratum to: Educ Psychol Rev (2015)}

\section{DOI 10.1007/s10648-015-9313-7}

The original version of this article unfortunately contained a mistake. The author names Sarah $\mathrm{K}$. Tauber and Uma Tauber are the same person. Thus, the latter was removed in the author line of this article.

The online version of the original article can be found at http://dx.doi.org/10.1007/s10648-015-9313-7.

\section{Bridgid Finn}

bfinn@ets.org

Sarah K. Tauber

uma.tauber@tcu.edu

1 Educational Testing Service, 660 Rosedale Road, Princeton, NJ 08541, USA

2 Department of Psychology, Texas Christian University, Box 298920 2800, S. University Dr, Fort Worth, TX 76129, USA 